\title{
The burden of cardiovascular disease in sub-Saharan Africa
}

\section{Anthony Mbewu}

Medical Research Council, Parow

Address for correspondence:

Prof A.D. Mbewu

Medical Research Council

Francie van Zijl Drive

Parow

7500

South Africa

Email:

anthony.mbewu@mrc.ac.za

\section{INTRODUCTION}

Cardiovascular disease (CVD) is a growing cause of death and disability in South Africa and the rest of sub-Saharan Africa - partly as a result of the increasing prevalence of determinants and risk factors for CVD in these societies in transition. This process was dubbed "the epidemiological transition" by Omran:(1) a concept further developed by Olshansky(2) and Pearson. ${ }^{(3)}$ The epidemiological transition in turn, is predicated upon demographic and nutritional transitions occurring as a result of socio-economic development and increasing globalisation that alter the determinants and risk factors for CVD and hence the patterns of CVD.

In most African countries CVD is now the second commonest cause of death after infectious disease, accounting for 10\% of total deaths ${ }^{(4)}$ and it is estimated that this burden of CVD will double from 1990 to 2020.

\section{THE EPIDEMIOLOGICALTRANSITION}

The "epidemiological transition" comprises of four stages shown in Table I.

Three main drivers fuel this epidemiological transition:

I. Declining infant and child mortality has lead to rapid demographic changes resulting in large increases in the number of

\section{ABSTRACT}

The burden of cardiovascular disease (CVD) in Africa is growing and changing in nature. From the predominance of rheumatic heart disease and cardiomyopathies $\mathbf{5 0}$ years ago to hypertensive heart disease and haemorrhagic stroke in the past $\mathbf{2 5}$ years. Albeit at low prevalence, an increase in incidence of ischaemic heart disease is now being seen, particularly in urban areas. These changes in the extent and nature of CVD are thought to be the result of the so-called "epidemiological transition". The challenge for health promotion and prevention is to accelerate the course of that transition and blunt its magnitude in order to avoid the massive epidemics of CVD that were seen in Europe and the USA in the mid-twentieth century. SAHeart 2009; 6:4-10

individuals surviving until middle and older age, when CVD becomes manifest - the so-called demographic transition. By 2025 it is estimated that the number of Africans over 60 years old will increase from 39 million to 80 million.

2. Falling death rates from communicable diseases accompany socio-economic development, improved vaccination and other primary health care services.

3. Socio-economic development results in changes in environmental and behavioural determinants of CVD, such as increasing tobacco use, increasing fat and calorie consumption, and physical inactivity. Longer periods of exposure to these determinants because of longer life expectancy increase the prevalence of CVD.

African countries are progressing through the epidemiological transition at a more rapid pace than occurred in Europe and America. This is partly due to rapid globalisation resulting in the "export of risk factors" such as tobacco, refined foods, and lifestyles with high CVD risk that are portrayed on television and film. ${ }^{(5)}$

Furthermore different sectors of society within a country move through the transition at different rates.(6) In South Africa for example the white population is in stage IV; coloured and Indian 
and middle class black Africans are in stage III; whilst the 70\% of South Africans (mainly black African) who are poor or very poor are in stages I and II. The challenge for the next twenty years in South Africa is to ensure that the latter group, as they become progressively wealthier, do not enter stage III but pass rapidly through to stage IV. This can most effectively be achieved through health promotion including primary prevention, delivered at community and primary health care level, focussing on the 5 major risk factors for CVD of smoking, high blood pressure, bad diet (including high saturated and trans-saturated fats; as well as scanty fruit and vegetables), physical inactivity, and obesity.

African countries then face a double burden - of communicable diseases such as HIV and AIDS, TB and malaria; as well as CVD. The high levels of morbidity and premature mortality from CVD place a particular strain on African countries whose health systems are already struggling to cope with epidemics of infectious disease, perinatal and maternal disease.

The situation is exacerbated by the fact that CVD in Africa tends to occur earlier in life, resulting in socio-economic hardship as the breadwinner in the family dies or is disabled. In African countries more than half of CVD deaths occur among people between 30 and 69 years of age, an age 5 - 10 years below the equivalent group in Europe and North America. ${ }^{(7)}$

Furthermore, their predicament is only likely to worsen, because the majority of their populations are under 35 years of age, and the determinants and risk factors for CVD are already prevalent and increasing within this age group.
Although the classical risk factors for CVD seem to operate in much the same way in all South African ethnic groups as they do in high income countries, their manifestations differ somewhat. For example, stroke supervenes at a younger age and haemorrhagic stroke is more common than thrombotic stroke.

Similar shifts in CVD pattern occurred in high income countries in the 1940s and 50s; but now low and middle income countries account for $82 \%$ of global mortality and $88 \%$ of mortality and morbidity from CVD. ${ }^{(4)}$

\section{RHEUMATIC HEART DISEASE}

In the 1980s, most of sub-Saharan Africa was in stage I of the epidemiological transition; and rheumatic heart disease (RHD) accounted for $10 \%$ to $35 \%$ of hospital cardiac patients in subSaharan Africa ${ }^{(8)}$ and up to $20 \%$ of cardiac deaths noted at autopsy. In Soweto, Johannesburg, the incidence of RHD among primary school children was 6.9 per I 000; and in Ibadan, Nigeria, the incidence was 3 per 1000 among children. ${ }^{(8)}$ This is particularly tragic as RHD is completely preventable having been virtually eradicated in most high income countries over the past 50 years. It is a disease of poverty, related to overcrowding, poor housing, and undernutrition and requires a multi-sectoral response for prevention and cure. It is caused by group A beta-haemolytic streptococci. The principal methods of control are primary and secondary prevention of streptococcal infection.

\section{FETAL ORIGINS OF CARDIOVASCULAR DISEASE}

Formerly CVD was seen as a disease of affluence; but the reverse is in fact true. Poor socio-economic conditions in child-

TABLE I: Epidemiological transition

\begin{tabular}{|c|c|c|c|}
\hline Phase of epidemiologic transition & Details from circulatory disease (\%) & Circulatory problems & Risk factors \\
\hline Age of pestilence and famine & $5-10$ & $\begin{array}{l}\text { Rheumatic heart disease, infection and } \\
\text { deficiency-induced cardiomyopathy }\end{array}$ & $\begin{array}{l}\text { Uncontrolled infection, deficiency } \\
\text { conditions }\end{array}$ \\
\hline Age of receding pandemics & $10-35$ & $\begin{array}{l}\text { As above, plus hypertensive heart } \\
\text { disease and hemorrhagic stroke }\end{array}$ & $\begin{array}{l}\text { High-salt diet leading to hypertension, } \\
\text { increased smoking }\end{array}$ \\
\hline $\begin{array}{l}\text { Age of degenerative and } \\
\text { man-made diseases }\end{array}$ & $35-55$ & $\begin{array}{l}\text { All forms of stroke, ischaemic heart } \\
\text { disease }\end{array}$ & $\begin{array}{l}\text { Atherosclerosis from fatty diets, } \\
\text { sedentary lifestyle, smoking }\end{array}$ \\
\hline Age of delayed degenerative diseases & Below 50 & $\begin{array}{l}\text { Stroke and ischaemic heart disease } \\
\text { at older ages }\end{array}$ & $\begin{array}{l}\text { Education and behavioural changes } \\
\text { leading to lower levels of risk factors }\end{array}$ \\
\hline
\end{tabular}

Pearson et al. 1993, 8 based on Omran 1971, 3 and Olshansky and Ault 1986 
hood determine CVD in middle age as strongly as do CVD risk factors in middle age in the same individuals. ${ }^{\left({ }^{(9)}\right.}$ Furthermore, in humans, birth size serves as a marker of the intrauterine environment. In 1995 David Barker wrote: "The fetal origins hypothesis states that fetal undernutrition in middle to late gestation, which leads to disproportionate fetal growth, programmes later coronary heart disease" and hypertension. ${ }^{(10)}$ The highest risk of coronary heart disease is seen among individuals who were born small and became heavier during childhood,(II) so-called "catch-up growth".

\section{EPIDEMIOLOGY OF CARDIOVASCULAR DISEASE}

\section{IN AFRICA}

Epidemiological data on CVD in Africa is scanty and of poor quality and national vital registration is available in only $5 \%$ of Africa's 53 countries. ${ }^{(12)}$ Verbal autopsy has been shown to be an economical and useful way of improving the quality of cause-of-death information when health workers have minimal training.(12)

Sentinel surveillance has also proven useful in monitoring changes in CVD prevalence with disease surveys periodically conducted at sentinel sites that are broadly representative of the general population. Demographic health surveys are conducted in several African countries including South Africa. ${ }^{(13)}$

The importance of CVD mortality in sub-Saharan African countries tends to be underestimated, because crude mortality rates are used. Age-standardised mortality ratios (Table 2 ) however, reveal that several African countries are in the throes of an epidemic of CVD - where those who survive infant deaths and infectious disease in young adulthood - proceed to experience mortality rates in middle and later life that are sometimes higher than for Scotland and Finland. ${ }^{(14)}$

\section{TABLE 2: Age-standardised death rates per 100000 in the year 2000}

\begin{tabular}{|l|c|c|c|c|c|}
\hline & $\begin{array}{c}\text { Black } \\
\text { African }\end{array}$ & White & Coloured & $\begin{array}{c}\text { SA of } \\
\text { Indian } \\
\text { descent }\end{array}$ & $\begin{array}{c}\text { South } \\
\text { Africa }\end{array}$ \\
\hline All Causes & 1613 & 937 & 1304 & 1172 & 1468 \\
\hline $\begin{array}{l}\text { Cardiovascular } \\
\text { diseases }\end{array}$ & 375 & 384 & 406 & 607 & 361 \\
\hline \hline
\end{tabular}

Comparative risk factor assessment, 2006 Bradshaw et al. MRC

\section{CORONARY HEART DISEASE}

The prevalence of CVD continued to rise through the 1980s becoming the third most common cause of death in a prospective autopsy study in 90 of the 167 deaths in one year at Tshepong Hospital in the North West province of South Africa. ${ }^{(15)}$ Of these CVD deaths, 32\% were cerebrovascular events, (intracerebral hemorrhage in 50\%, cerebral infarction in 29\%); pulmonary hypertension in $31 \%$; dilated cardiomyopathy 17\%; chronic rheumatic valvular disease 17\%; and hypertensive heart disease $14 \%$. Only $3 \%$ of the examined vessels had signs of severe atherosclerosis.

Even as late as 1997, coronary artery disease ranked only eighth among the CVD registered in Cameroon with a prevalence of 1.53\%. However, risk factors for coronary disease were common amongst those with coronary disease in this 5-year prospective study with obesity occurring in $80 \%$, hypertension in $60 \%$, dyslipidaemia in 43\%, smoking in 36\% and diabetes/ hyperglycaemia in $26 \%$. Seventy six percent of the patients had at least 3 cardiovascular risk factors. ${ }^{(16)}$

In South Africa coronary disease is the major cause of death among white people and South Africans of Indian descent, with incidence rates of 165.3 and 101.2 per 100000 people respectively but only 55.1 per 100000 among people of mixed descent and 5.3 per 100000 among black African people. Cerebrovascular disease is the commonest cause of CVD death among those of mixed descent, followed by white people and South Africans of Indian descent, and then black African people (73.6, 62.5, and 36.5 per 100000 , respectively). ${ }^{(14)}$

The increase in coronary heart disease $(\mathrm{CHD})$ in sub-Saharan Africa is presumably because of the increasing prevalence among African populations of the classical risk factors for CHD: smoking, a diet high in saturated fat, hypertension, obesity, diabetes mellitus, and lack of physical exercise. In addition, life expectancy in subSaharan Africa has risen so that more people are exposed to these risk factors for long enough periods to cause CHD. A study of black African patients admitted to a coronary care unit with acute myocardial infarction between 1995 and 1996 showed high rates of smoking and hypertension among the patients compared with controls matched by age and sex. ${ }^{(17)}$ 
In patients with newly diagnosed cardiovascular disease (CVD) presenting to a tertiary-care centre (Chris Hani Baragwanath Hospital in Soweto, South Africa) the most common conditions among these patients were hypertension, heart failure, valvular heart disease, and coronary artery disease. ${ }^{(7)}$ Artherosclerotic risk factors were widely prevalent, only 13\% of patients had no risk factors at all. Furthermore, a substantial proportion of patients presented at an advanced stage of disease.

A coronary angiographic study of black African patients with acute myocardial infarction and acute ischaemic syndromes admitted to Chris Hani Baragwanath Hospital in Johannesburg, South Africa showed a clear increase in prevalence of risk factors for CHD in these patients compared with age- and sex-matched controls. ${ }^{(18)}$

\section{STROKE}

Stroke is probably the commonest form of CVD in sub-Saharan Africa today, having increased in the latter half of the twentieth century as a result of increased life expectancy and changes in environmental determinants and risk factors. The majority of strokes occur in young and middle-aged people and are related to hypertension. Stroke accounted for $5 \%$ of deaths in South Africa in 2006.(19) Though the number of reported stroke deaths has more than doubled since 1995 (reaching 34926 deaths in 2006), the actual proportion of total deaths has fallen from $6.6 \%$ in 1995 to $4.6 \%$ in 2006 of total deaths due to the tripling of number of deaths largely due to HIV and AIDS and tuberculosis.

\section{HYPERTENSION}

Hypertension is highly prevalent in sub-Saharan Africa (12\% amongst adults in the SADHS of 2002) and is often undetected or poorly controlled. This may be the explanation for the high proportion of hemorrhagic cerebrovascular accidents (CVAs), whereas in developed countries most CVAs occur in older people and are thrombotic in etiology.

Systemic hypertension is the commonest cause of heart failure among black Africans. Early detection and control of systemic hypertension should be more aggressively pursued.(7)

The global INTERHEART study demonstrated that nine easily measured risk factors are associated with more than $90 \%$ of the risk of myocardial infarction. ${ }^{(20)}$

\section{DILATED CARDIOMYOPATHY}

Dilated cardiomyopathy (DCM) resulting in congestive cardiac failure is surprisingly common in sub-Saharan Africa, accounting for up to $20 \%$ of cardiac cases in some regions. Occasionally the disease is familial with specific candidate genes recently identified. ${ }^{(21)}$ There may be a whole spectrum of causes of DCM, including genetic etiology, toxins, and vitamin or micronutrient deficiency, such as selenium deficiency. Dilated cardiomyopathy is often seen as a late complication of HIV infection. ${ }^{(22)}$

\section{ENDOMYOCARDIAL FIBROSIS}

Endomyocardial fibrosis is the most common restrictive cardiomyopathy worldwide. ${ }^{(23)}$ It has no specific treatment and carries a poor prognosis, since most patients present with advanced heart failure. It involves fibrosis of the inflow tracts of the right and left ventricles resulting in mitral or tricuspid incompetence; and impaired ventricular function, as a result of the restrictive deficit in which the stiff fibrotic ventricles cannot contract and relax normally. Patients usually present in their twenties or thirties.

On the basis of clinical series, regional variations in distribution have been reported within several countries in Africa between the Sahara Desert in the north and the Zambezi River in the south; as well as in Asia and South America, but large-scale data on the epidemiologic features and early stages of the disease only recently became available.(24) Mocumbi et al using transthoracic echocardiography to determine the prevalence of endomyocardial fibrosis in a rural area of Mozambique, estimated overall prevalence of endomyocardial fibrosis at $19.8 \%$. The prevalence was highest among persons 10 to 19 years of age (28.1\%); and was higher among male than among female subjects (23.0\% vs. $17.5 \%, \mathrm{P}=0.03)$. The most common form was biventricular endomyocardial fibrosis (56\%), followed by right-sided endomyocardial fibrosis (28\%). The frequency of familial occurrence was high and $77 \%$ of cases were asymptomatic.

In temperate climates the disease is rare, presenting as Loeffler's endocarditis, a syndrome with marked eosinophilia. Consequently it has been suggested that EMF may be caused by an eosinophilic response to filariasis or malaria. ${ }^{(8)}$ 


\section{HIV DISEASE ANDTHE HEART}

It is now evident that cardiac involvement in patients with HIV and AIDS is relatively common. The effects occur in three ways: by direct invasion; ${ }^{(25)}$ through the effects of opportunistic infections as a result of AIDS; and as side-effects of the treatment of HIV disease with antiretrovirals, particularly due to the longer survival of patients infected with HIV.

People living with HIV and AIDS have evidence of cardiac involvement at post mortem (40\%) and by echocardiography (25\%).(22) However, fewer than 10\% ever experience symptoms. Cardiac involvement is the cause of death in only $1 \%$ to $2 \%$ of patients infected with $\mathrm{HIV}^{(24)}$ but this may change as hundreds of thousands of Africans are initiated onto antiretroviral therapy, particularly protease inhibitors.

Dilated cardiomyopathy is a late manifestation of HIV disease and the mechanism may include myocarditis due to HIV itself or the deficiencies of carnitine, selenium and thiamine that supervene in AIDS. This may therefore be exacerbated in Africa where malnutrition is already rife. Cardiotoxicity of some drugs such as zidovudine has also been described.

Coronary disease may occur as a result of the dyslipidaemia, glucose intolerance, increased levels of C peptide, and endothelial dysfunction associated with some antiretroviral drugs, particularly protease inhibitors and nucleoside reverse transcriptase inhibitors. The incidence of diabetes is increased 3-fold in those on HAART. The vessel involvement is frequently diffuse and circumferential along the whole artery. ${ }^{(25)}$ Other mechanisms may include altered coagulation in HIV disease, as well as changed adhesion properties of vascular monocytes. Coronary event incidence rates of 5.5 per I 000 patient-years in patients receiving HAART have been reported. ${ }^{(25)}$ Myocardial infarction is the mode of presentation in up to $76 \%$ and cebrovascular events are also common. ${ }^{(25)}$

HIV and AIDS also cause stroke, pulmonary embolism, tuberculous pericarditis, marantic (non-bacterial) endocarditis, autonomic dysfunction, and proarrhythmic drug effects. In a recent review of 17 peer-reviewed publications covering January 1980 to February 2003 on cardiac involvement in HIV-infected people living in Africa, Magula and Mayosi(26) confirmed that cardiac abnormalities are more common in HIV-infected people than in normal controls and that about half of hospitalised patients and a significant proportion of patients followed over several years develops cardiac abnormalities.

The most common HIV-related cardiac abnormalities are cardiomyopathy (in $20 \%$ before the advent of HAART), and pericardial disease (in 20\% of patients). Tuberculosis is the major cause of large pericardial effusion in Africa. HIV-related pericardial effusions are usually exudates and tend to occur in patients with advanced disease, with an annual incidence of 10\%. They are an independent risk factor for early death, with mortality at six months of $62 \%$ in those with effusions compared to $7 \%$ in those without. ${ }^{(24)}$

Infective endocarditis is also common in HIV disease; though with the introduction of HAART the incidence declined from 20.6 to 6.6 per I 000 patient years. ${ }^{(25)}$

Patients living with HIV and AIDS may also suffer from the cardiac effects of the malignancies that commonly occur in AIDS, such as Kaposi' sarcoma and Hodgkin's lymphoma.

The prevalence of hypertension is increased 3-fold in patients on HAART ${ }^{(25)}$ and the prevalence of pulmonary hyper-tension increased from I in 200000 in the general population to I in 200.(25)

\section{CONGENITAL HEART DISEASE}

Children in Africa suffer from rheumatic heart disease and sicklecell. Congenital heart disease has prevalence of 2.0 per | 000 with ventricular septal defect, atrial septal defect, patent ductus arteriosus, and Fallot's tetralogy making up $85 \%$ of the cases. ${ }^{(28)}$

\section{DYSRHYTHMIAS}

Atrial fibrillation is the most common cardiac arrhythmia in South Africa, with an incidence of about $8 \%$ of the population 
70 years and older. In a cardiac clinic in Soweto, South Africa $33 \%$ of patients had some form of arrhythmia; and $7 \%$ had atrial fibrillation. ${ }^{(7)}$

\section{PERICARDIAL EFFUSIONS}

A study carried out from 1989 to 1996 in the Republic of Congo found that $4.9 \%$ of patients with cardiovascular disease had nonrheumatic pericarditis with effusion. ${ }^{(28)}$ Twenty-two percent were HIV positive. The principal cause of the pericarditis was tuberculosis, which accounted for about a quarter of the patients, all of whom were HIV positive.

\section{URBAN RURAL DIFFERENCES}

At the beginning of the twentieth century, high blood pressure was virtually nonexistent among indigenous Kenyans ${ }^{(29)}$ and Ugandans, ${ }^{(8)}$ but the reason may have been the lack of screening programs and access to care. From about 1975, high blood pressure became established, especially in urban centres. Rural-to-urban migration coupled with acculturation and modernisation trends have some relation to the development of high blood pressure, whose prevalence varies from 5\% amongst rural African cohorts to 15\% in urban areas. ${ }^{(30,31)}$

Among the Luo of Kenya, increasing blood pressure within months of migrating from the rural areas to the city has been recorded, with concomitant increases in their dietary sodium and declines in their dietary potassium. ${ }^{(29)}$

In South Africa, even rural populations have high rates of noncommunicable disease, which accounted for $41 \%$ of deaths in those aged 50 and older in a rural demographic site in the eastern part of South Africa. ${ }^{(33)}$

\section{CONCLUSION}

To date no evidence has been found that Africans have esoteric, genetically determined risk factors for CVD that differ from other populations in the world; nor do they appear to have special genetic traits that protect them from heart disease. It seems likely that the continuing socio-economic advance in many African countries over the next 50 years will be accompanied by the attendant increases in CVD that were seen in epidemiological transitions across the world over the past 50 years.

$\mathrm{CHD}$ and strokes share common determinants and risk factors and are more common in urban than rural areas. Any suggestion that people of black African descent are in some way immune from CVD has been dispelled by well-documented evidence from, among other countries, Cameroon, Caribbean countries, Mauritius, the Seychelles, South Africa, Tanzania, and the United States. In such countries CVD already accounts for between I5\% and 40\% of all deaths.

The challenge is to introduce primary and secondary prevention measures now, before the epidemic of CVD accelerates, particularly as such strategies may be more cost-effective than angioplasty and cardiac surgery in the cash-strapped economies of sub-Saharan Africa.

The costs of intersectoral, primary preventive measures to control CVD are likely to be much lower than those for acute, secondary care. As an example, the cost-effectiveness of introducing antitobacco legislation, and limiting the quantities of salt permitted in processed food. Such health promotion interventions should be coupled with primary health care systems delivering secondary prevention, treatment and care for CVD. 


\section{REFERENCES}

I. Omran AR. The Epidemiological Transition: A key of the epidemiology of population change. Milbank Memorial Fund Quarterly 1971; 49:509-38.

2. Olshansky SJ, Ault B. The fourth stage of the epidemiologic transition: The age of delayed degenerative diseases. The Milbank Quarterly 1986;64:355-387.

3. Pearson TA, Jamison DT, Trejo-Guitireez H. Cardiovascular disease. In: Jamison DT, Mosely WH, Measham AR, Bobadilla JL, eds. Disease control priorities in developing countries. New York: Oxford University Press, 1993:577-599.

4. Global burden of disease update 2004.WHO 2008. Geneva, Switzerland.

5. Mbewu AD. 1998. "Can developing country systems cope with the epidemics of cardiovascular disease?"' Heart Health Conference, New Delhi, India.

6. Chronic diseases of lifestyle in South Africa 1995-2005. MRC technical report. Editors: Steyn K, Fourie J. Temple N. Medical Research Council 2006, Parow, South Africa.

7. Sliwa K, Wilkinson D, Hansen C, et al. Spectrum of heart disease and risk factors in a black urban population in South Africa (the Heart of Soweto Study): a cohort study. Lancet 2008;371:915-922.

8. Hutt M. 1990. Cancer and cardiovascular diseases. Chapter 15 In "Disease and mortality in sub-Saharan Africa". Editors Jamieson D, Feacham R. Publishers: Oxford University Press for the World Bank.

9. Lawlor D, Davey Smith G, Ebrahim S. 2002. Birth weight of offspring and insulin resistance in late adulthood: cross sectional survey. British Medical Journal 2002;325:359-362.

10. Hales CN, Barker DJP. Type 2 (non-insulin dependent) diabetes mellitus: the thrifty phenotype hypothesis. Diabetologia 1992;35:595-60 I.

।1. Eriksson JG, Forsén T, Tuomilehto J, et al. Catch-up growth in childhood and death from coronary heart disease: Iongitudinal study. British Medical Journal. 1999:318;427-31

12. Sen K, Bonita R. Global Health Status: Two steps forward, one step back. Lancet 2000:356:577-82.

13. South Africa demographic and health survey 2002. Pretoria: National Department of Health.

14. Bradshaw D, Groenewald P, Laubscher R, et al. Initial burden of disease estimates for South Africa, 2000. 2003. Parow: South African Medical Research Council.

15. Steenkamp J, Simson I, Theron W. Cardiovascular causes of death at Tshepong Hospital in I year, 1989-1990. A necropsy study. South African Medical Journal 1992;8 I (3): | 42-46

16. Mbanya JC, Minkoulou E, Salah J, et al. "The prevalence of hypertension in rural and urban Cameroon." International Journal of Epidemiology 1998;27:|8|-85.

17. Mayosi B, Mbewu A. Risk factors for coronary heart disease in patients admitted to a coronary care unit in Cape Town, South Africa. Canadian Journal of Cardiology; 1996.

18. Nethononda MR, Essop MR, Mbewu A, et al. Coronary artery disease and risk factors in black South Africans - A comparative study. Ethnicity and disease 2004; 1 4:5 15-19.

19. Mortality and causes of death in South Africa, 2003 and 2004. Findings from death notification. Statistics South Africa, 2006. Pretoria, South Africa.

20. Yusuf SS, Hawken S, Ounpuu S, et al. Effect of potentially modifiable risk factors associated with myocardial infarction in 52 countries (the INTERHEART Study). Lancet 2004:364:937-52.

21. Sliwa K, Damasceno A, Mayosi B. Epidemiology and etiology of cardiomyopathy in Africa. Circulation 2005:112:3577-83.
22. Fauci AS, Lane HC. "Human Immunodeficiency Virus (HIV) disease: AIDS and related disorders." In Harrison's Principles of Internal Medicine, 16th ed. 2007 New York: McGraw-Hill.

23. Davies JN. Endocardial fibrosis in Africans. East African Medical Journal 1948; 25:10.

24. Mocumbi AO, Ferreira MB, Sidi D, et al. A population study of endomyocardial fibrosis in a rural area of Mozambique. N Engl J Med. 2008 Jul 3;359( I):43-9.

25. Boon N. Cardiac disease in HIV infection. In Oxford Textbook of Medicine 2003. ed.Warrell DA, CoxTM, Firth JD. Oxford: Oxford University Press.

26. Mayosi B, Burgess ML, Doubell AF. Tuberculous pericarditis. Circulation 2005 1 12:3608-16.

27. Khalii SI, Gharieb K, El-Haj M, et al. Prevalence of congenital heart disease among school children of Sahafa Town, Sudan. Eastern Mediterranean Health Journal 1997:3:24-28.

28. Nkoua J L, Tsombou B, Bouramoue C. Non-rheumatic pericarditis with effusion: causes, outcome and relation to HIV infection. Annals of Oncology 1999, 25:3-6.

29. Lore W. Epidemiology of cardiovascular diseases in africa with special reference to Kenya: an overview. East African Medical Journal 1993;70:357-61.

30. Mokhobo KP. Arterial Hypertension in rural societies. East African Medical Journal 1976;52:440-44.

31. Seedat YK, Seedat MA, Hackland DB. Prevalence of hypertension in the urban and rural Zulu. Journal of epidemiology and community health 1982;36: 256-61.

32. Seedat YK, Seedat MA, Hackland DB. Prevalence of hypertension in the urban and rural Zulu. Journal of epidemiology and community health 1982;36: 256-61.

33. Tollman S, Kahn K, Sartorius B, et al. Implications of mortality transition for primary health care in rural South Africa: a population-based surveillance study Lancet 2008:372:893-901. 